\title{
A 'mystery shopper' project to evaluate sexual health and contraceptive services for young people in Croydon
}

\author{
Susie Sykes, Karin O'Sullivan
}

\begin{abstract}
Objective The purpose of the study was to evaluate the accessibility of, and advice provided by, sexual health and advice services for young people in Croydon, UK using a 'mystery shopper' approach.
\end{abstract}

Methods Nineteen young people aged 13-21 years were trained as mystery shoppers. The group developed a set of standards, based in part on existing guidelines of best practice, that should be met when working with young people. The group accessed local sexual health services in pairs posing as genuine patients. Using one of four scenarios, the mystery shoppers assessed the service they received against the predefined standards.

Results The main access difficulties occurred in the reception area. Confidentiality was a major concern and was frequently not explained. The advice and information received was generally clearly given and with an appropriate level of detail.

Conclusions Additional training and support needs to be offered to receptionists. Confidentiality policies and statements need to be more effectively communicated.

J Fam Plann Reprod Health Care 2006; 32(1): 25-26 (Accepted 23 September 2005)

\section{Key message points}

- A mystery shopper approach can be an effective and powerful way of identifying barriers facing young people when accessing services.

- The main barriers facing young people when accessing services occur in the reception area or when asking for the service they require.

- Confidentiality is a major concern for young people. Policies are not routinely explained, but when they are young people appreciate it and find the issues easy to understand.
Teenage Pregnancy Team, Department of Public Health, Croydon Primary Care Trust, Croydon, UK

Susie Sykes, BA, MA, Research and Evaluation Specialist Karin O'Sullivan, RGN, FP Specialist Sexual Health Nurse

Correspondence to: Ms Susie Sykes, Croydon Primary Care Trust, Department of Public Health, 12-18 Lennard Road, Croydon, Surrey CR9 2RS, UK. Tel: +44 (0) 2082746396. E-mail: susie.sykes@croydonpct.nhs.uk

\section{Introduction}

Within the Best Practice Guidance on the Provision of Effective Contraceptive and Advice Services for Young People 1 there is an emphasis on ongoing involvement of young people in the design, development and evaluation of services. The involvement of young people as researchers rather than simply as respondents is a relatively new approach to health service evaluation but there is a growing body of literature outlining the benefits and challenges this approach presents. ${ }^{2-4}$

Teenage conception rates in Croydon, UK are higher than the national average ${ }^{5}$ and the local strategic response encompasses the principles of participation of young people. It was within this context that the "mystery shopper' approach to evaluating young people's sexual health and advice services was developed. ${ }^{6}$

\section{Methods}

Following a period of planning and negotiation with service managers and providers, the project was advertised in youth groups, schools, colleges, Connexions and young mothers' support groups. Prospective mystery shoppers underwent an informal telephone interview and a mixed, though predominantly female, group of 19 young people, aged 13-21 years, was recruited (Table 1).

Intensive training provided opportunities for participants to explore the role of the mystery shopper, to discuss what a young person should expect from services, and to familiarise themselves with the scenarios to be used. Extensive role-play was employed to develop strategies to manage potential problems. During the training period the group developed a set of standards that they felt services should meet when working with young people. These standards were based, in part, on those developed by the Government's Teenage Pregnancy Unit. ${ }^{5}$

Four scenarios were developed that represented different situations that young people might find themselves in. A risk assessment process was undertaken to ensure that no young person would be required to undergo any form of examination, treatment or pregnancy test, or be offered any form of medication such as

Table 1 Details of mystery shoppers employed in the study

\begin{tabular}{llll}
\hline Gender & Age (years) & Ethnicity & Status \\
\hline Male & 17 & White British & College \\
Male & 17 & White British & College \\
Male & 15 & Asian British & School \\
Female & 13 & White British & School \\
Female & 15 & White British & School \\
Female & 21 & White British & Young mother \\
Female & 14 & White British & School \\
Female & 16 & Asian British & College \\
Female & 16 & Asian British & College \\
Female & 16 & Asian British & College \\
Female & 16 & Asian British & College \\
Female & 17 & Black British & College \\
Female & 16 & White British & School \\
Female & 19 & White British & Young mother \\
Female & 19 & White British & Young mother \\
Female & 14 & White British & School \\
Female & 14 & White British & School \\
Female & 15 & White British & School \\
Female & 16 & White British & School \\
\hline
\end{tabular}




\section{ARTICLE}

emergency contraception. The scenarios involved accessing services for:

- free condoms

- advice on different contraceptive options

- advice on options after discovering a pregnancy

- advice on emergency contraception.

Mystery shoppers had 2 weeks to visit services, in pairs, posing as genuine patients. An assessment form was completed after each visit by each mystery shopper. The questions on the assessment form related directly to the standards being used and were largely qualitative, allowing mystery shoppers to record, in detail, their observations and experiences.

\section{Analysis}

The participatory nature of the project was continued in the analysis stage, with the young people working alongside workers to identify, categorise and code themes through a process of re-reading and sorting assessment form data, reflection on the experience, and group discussion regarding interpretation of the data.

\section{Results}

Most of the participants found it relatively easy to get to the services but difficulties arose when asking reception staff for the service they required. There were examples of the mystery shoppers being told they were too young to use the service, that they did not need emergency contraception, that the service was not available and that they would have to wait 2 weeks for an appointment. One pair was told to wait in the street as the waiting room was full. Many of the young people found the receptionists very difficult to talk to:

"The receptionist told me that they did not give out information and it wasn't open. She was quite rude and shouted out what I wanted in front of people."

Confidentiality was a key issue that emerged from the study and only one service had a poster explaining their policy. During the majority of visits the confidentiality policy was not explained, either by reception staff or practitioners. When it was explained the young people all found it very easy to understand. Without an explanation the mystery shoppers found the whole issue of confidentiality rather confusing, particularly in relation to their rights.

The size of the waiting room, combined with the number of people waiting, caused concern and embarrassment when telling reception staff what was wanted. It was felt this reduced the confidential nature of the service and that staff did not acknowledge this as a difficulty:

"When we asked if we could talk to somebody, the whole waiting room was looking at us.'

On the whole, the mystery shoppers were very positive about the way they were treated by the clinical practitioners. Mystery shoppers appreciated it when staff were friendly, gave them time, explained things and showed care and concern:

"She was very helpful, it felt like she had time for me, she read through the leaflet with me and made sure I understood her."

Some mystery shoppers had a less positive experience, however, and the main issues that were commented on were a lack of time, a sense that staff were not interested or that they were not polite:

"The time they took, the tone they took - it was like they did not want to be there."
When the mystery shoppers spoke to a clinical practitioner they generally felt they received appropriate and thorough advice and information. Nobody left with emergency contraception they did not need, was offered an unnecessary pregnancy test or felt pressured into taking any form of contraception they did not need or want. The information they were given was generally felt to be easy to understand and there was sufficient detail for them to make informed decisions.

\section{Discussion}

The findings have confirmed other research findings regarding barriers facing young people when accessing sexual health services ${ }^{7}$ - particularly around confidentiality and difficulties in the reception area - but have also provided a local understanding and interpretation of those issues. The project has piloted a powerful way of exploring accessibility, resulting in very practical recommendations for improving services. ${ }^{6}$ The commitment to the participatory nature of this study has resulted in all services producing comprehensive action plans for service improvement in consultation with the young people involved and has therefore been successful in effecting change. This project involved a significant amount of time and support but produced extremely positive outcomes in terms of understanding a young person's experience of services.

\section{Statements on funding and competing interests}

Funding. None identified

Competing interests. Karin O'Sullivan has a clinical role within the family planning and genitourinary departments of Croydon Primary Care Trust.

\section{References}

1 Teenage Pregnancy Unit. Best Practice Guidance on the Provision of Effective Contraceptive and Advice Services for Young People. London, UK: Department of Health, 2000.

2 Clark J, Dyson A, Meagher N, Robson E, Wootten M (eds). Young People As Researchers: Possibilities, Problems and Politics. Leicester, UK: Youth Work Press, 2001

3 Kirby P. Involving Young Researchers. York, UK: Joseph Rowntree Foundation, 1999.

4 Worrall S. Young People As Researchers: A Learning Resource Pack. London, UK: Save the Children, 2000.

5 Teenage Pregnancy Prevention and Support, Croydon Strategy 2001-2010. Croydon, UK: Croydon and Surrey Downs Community NHS Trust, 2000

6 Sykes S, O'Sullivan K. 'Some of Us Couldn't Get In and Some of Us Couldn't Get Out.' 2004. Project report available from the authors.

7 Brook Advisory Centres/Egg Research and Consultancy. 'Someone With a Smile Would be Your Best Bet.' Coventry, UK: Brook Publications, 1998.

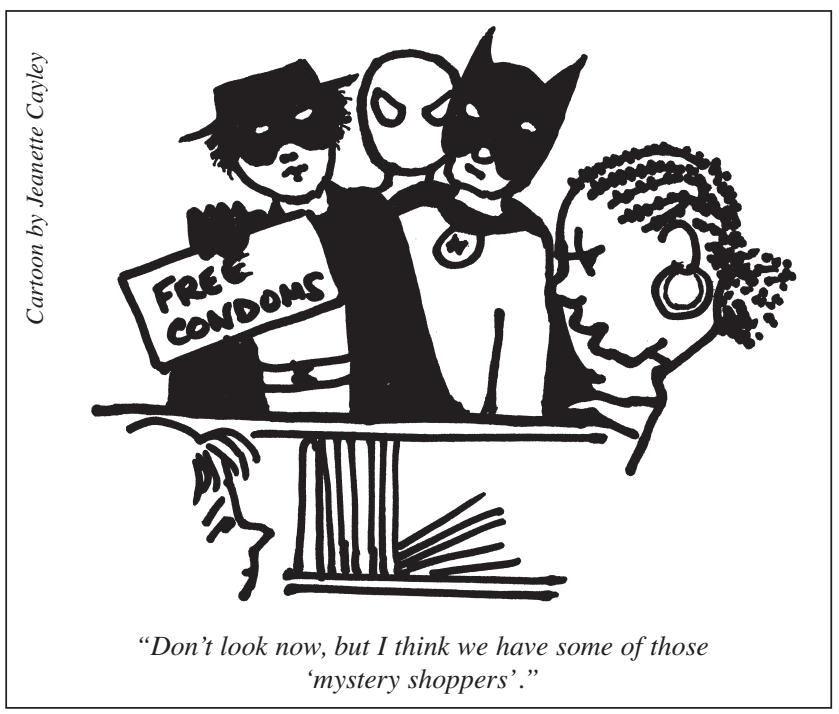

